\title{
INICIATIVAS DE COLETA SELETIVA E \\ LOGÍSTICA REVERSA EM PORTO ALEGRE \\ COMO BASE PARA ECONOMIA CIRCULAR
}

\section{SELECTIVE WASTE COLLECTION AND REVERSE LOGISTICS INITIATIVES IN PORTO ALEGRE AS BASIS FOR A CIRCULAR ECONOMY}

\author{
ANELISE TODESCHINI HOFFMANN, M.SC.| UFRGS \\ JOCELISE JACQUES DE JACQUES, Dra. | UFRGS
}

\begin{abstract}
RESUMO
A economia circular tem como base o retorno de materiais ao ciclo produtivo e isto só é possível quando há coleta seletiva e logística reversa. Desde antes do conceito de economia circular se tornar popular na pauta ambiental já se reconhecia que uma das estratégias mais efetivas para a diminuição dos resíduos é o controle do material descartado através de sua coleta, desmonte e processamento para que retorne como insumo no processo industrial. Com a aprovação da Lei Federal 12.305, fabricantes, importadores, distribuidores e comerciantes são corresponsáveis pelos resíduos sólidos e rejeitos envolvidos em todo o processo, o que traz incentivos à logística reversa. Neste contexto, apresentamos a situação atual da coleta seletiva no país e em Porto Alegre (considerada vanguardista no Brasil), e as iniciativas de logística reversa. Este levantamento mostrou que, mesmo depois de mais de 30 anos de coleta seletiva, a cidade ainda necessita de campanhas de conscientização da população em gerar menos resíduo e destiná-lo corretamente. Mesmo extremamente necessário e fundamental para a abordagem da economia circular, é necessário ainda muito investimento em tecnologia, educação e gestão, para que os benefícios da aplicação da logística reversa, como redução de custos com matéria-prima e promoção da responsabilidade socioambiental possam ser colhidos no Brasil.
\end{abstract}

PALAVRAS-CHAVE: coleta seletiva; logística reversa; economia circular

\begin{abstract}
One of the strategies for waste reduction is control of discarded materials through collection, disassembly and processing so that it can return as input for industrial processes. With approval of federal law 12,305 in Brazil, manufacturers, importers, distributors and retailers have become co-responsible for the treatment or disposal of post-consumer products, thus incentivizing reverse logistics. In this context, this paper presents the current status of reverse logistics in the country and particularly in the city of Porto Alegre (considered a precursor in Brazil), and reverse logistics initiatives. Even more than 30 years after first introducing its selective waste collection system, the city still needs public awareness and education campaigns for citizens to generate less waste and correctly separate, dispose or return it to producers. Considering the fundamental importance for a circular economy approach, considerable investments in technology, education and waste management are needed so that the benefits of reverse logistics - such as reduced costs and extraction of raw materials, social and environmental responsibility - can be fully enjoyed in the country.
\end{abstract}

KEYWORDS: selective collect; reverse logistic; solid waste; circular economy; 


\section{INTRODUÇÃO}

O agravamento dos impactos ambientais causados pelos modelos de produção e hábitos de consumo da população global tem levado a discussões sobre a necessidade de repensar os sistemas econômicos atuais com o intuito de mitigar os efeitos das mudanças climáticas que ameaçam, não só o meio ambiente, como também a economia e a saúde da parcela mais vulnerável da sociedade (PEIXOTO, et al. 2019). Considerando também que a utilização de energias renováveis atingiria $55 \%$ das emissões dos gases do efeito estufa, e que os $45 \%$ restantes ainda são resultado direto de como usamos produtos e alimentos, segundo dados de Ellen MacArthur Foundation (2017), torna-se fundamental a reflexão sobre a importância do retorno dos materiais ao ciclo produtivo depois de descartados. Embora não seja um tema recente, pois há anos iniciativas práticas podem ser avaliadas, estas iniciativas estão ligadas especialmente às administrações municipais e como elas encaram a questão dos resíduos.

Com o aumento da descartabilidade dos produtos, impulsionado pela sociedade de consumo, surge uma das questões mais urgentes das cidades e grandes centros, que é a disposição do lixo urbano (PEIXOTO, et al. 2019). Conforme Lesina (2018) a geração de dejetos no Brasil cresce mais do que a população, de 2003 a 2014, a produção de lixo aumentou $29 \%$, enquanto o avanço populacional foi de $6 \%$. O autor destaca também que, de acordo com Política Nacional de Resíduos Sólidos (PNRS), R\$ 8 bilhões são perdidos por ano no país com resíduos sólidos que deveriam ser reciclados, já que mais de $90 \%$ do resíduo gerado no Brasil é disposto no solo, sem qualquer aproveitamento.

Uma vez que a quantidade e variedade de resíduos só tem aumentado e parece não existir nenhum esforço para a redução do consumo, a reciclagem é apresentada como uma das soluções mais utilizadas para diminuir o impacto dos resíduos sólidos (SILVA e NASCIMENTO, 2017). Para os autores, a coleta seletiva viabiliza a maior efetividade da reciclagem, pois incentiva a separação prévia do material diretamente na fonte geradora, evitando possível contaminação pela matéria orgânica, possibilitando maior aproveitamento dos materiais e diminuição dos custos de reciclagem. Neste sentido, dentro do campo de desenvolvimento de produto é fundamental que designers conheçam o tema, que inclui o conhecimento sobre materiais e suas possibilidades de reciclabilidade ou compostabilidade, e também as condições de coleta seletiva e redes de logística reversa.

Esta preocupação deve pautar as decisões de projeto e incentivar ações de fabricantes que assimilem a responsabilidade pelos produtos que colocam no mercado. Por outro lado, a sociedade também deve ser incentivada a conduzir seus resíduos da melhor forma possível. O conhecimento sobre pontos de coleta e sobre as características do fim de ciclo de vida de cada material deve ser melhor divulgado nos produtos, e em campanhas de informação. A adesão à coleta seletiva ainda é uma opção individual, mas em uma sociedade bem informada forma-se uma rede em que a melhor decisão para a comunidade acaba por preponderar.

Para refletir sobre o que já está sendo feito, o presente artigo tem como objetivo apresentar a situação atual da coleta seletiva no país e, em especial na cidade de Porto Alegre, que é considerada vanguardista no Brasil. Porto Alegre desde 1990, opera com o sistema de coleta seletiva, que iniciou com um projeto piloto em um bairro e hoje atende $100 \%$ da cidade. No texto são apresentadas as iniciativas de logística reversa que aos poucos estão sendo aplicadas na cidade, tendo em vista a Lei Federal 12.305 (2010), apontando os problemas ainda existentes para sua implementação de forma mais abrangente. Para este levantamento foram utilizados dados e informações disponíveis no site oficial da Prefeitura de Porto Alegre, assim como, em matérias de reportagens publicadas em jornais locais.

\section{LOGÍSTICA REVERSA E A LEI FEDERAL 12.305}

Ao final de todos os processos logísticos de produção e distribuição de produtos industriais são descartadas quantidades enormes de materiais: resíduos industriais, materiais de embalagem, produtos devolvidos por clientes (com ou sem uso), peças decorrentes de manutenção, veículos, equipamentos, material de escritório entre outros (GUARNIERI, 2013).

No fluxo linear da logística tradicional, o produto novo é produzido, estocado, expedido, distribuído e consumido, tendo o descarte como final de sua vida útil. Enquanto o fluxo cíclico, em que a logística reversa é elemento fundamental, está relacionado ao retorno de produtos e embalagens pós-consumo ao processo produtivo como matéria-prima secundária (McDONOUGH e BRAUNGART, 2002; SOUZA, DE PAULA e SOUZA-PINTO, 2012). Desta forma o processo de Logística Reversa se inicia quando acaba a Logística Direta na produção de produto (suprimentos - produção - distribuição - consumo) formando um ciclo logístico fechado, pois com a entrega do produto ao cliente final são gerados materiais que necessitam ser reinseridos no ciclo produtivo novamente, como pode ser visualizado no esquema apresentado na Figura 1. 


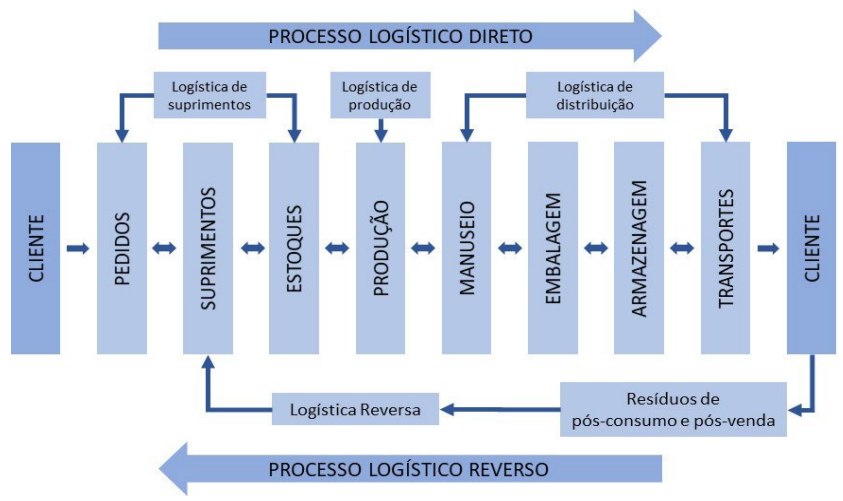

Figura 1: Logística direta versus logística reversa. Fonte: autoras, adaptado de Guarnieri (2013).

A Logística Reversa (LR), portanto, relaciona-se às atividades de coletar, desmontar e processar produtos usados ou partes de produtos, de modo a assegurar uma recuperação, do ponto de vista ambiental.

A Lei Federal no 12.305/2010 define LR como:

um instrumento de desenvolvimento econômico e social caracterizado por um conjunto de ações, procedimentos e meios destinados a viabilizar a coleta e a restituição dos resíduos sólidos ao setor empresarial, para reaproveitamento, em seu ciclo ou em outros ciclos produtivos, ou outra destinação final ambientalmente adequada.

A criação desta Lei n. 12.305 (2010), que organiza a forma com que nosso país lida com os resíduos, responsabilizando a indústria que produz, quem vende e quem descarta. Foi um marco, por tratar de todos os resíduos sólidos e rejeitos incentivando o descarte correto (com a redução de resíduos e fim dos lixões), prevendo também práticas de educação sanitária e ambiental, incentivos fiscais e a logística reversa.

Desde 2010 esta lei institui a PNRS, onde os fabricantes, importadores, distribuidores e comerciantes de produtos como: (i) agrotóxicos, seus resíduos e embalagens; (ii) pilhas e baterias; (iii) pneus; (iv) óleos lubrificantes, seus resíduos e embalagens; (v) lâmpadas fluorescentes, de vapor de sódio e mercúrio e de luz mista; e (vi) produtos eletrônicos e seus componentes, "são obrigados a estruturar e implementar sistemas de logística reversa, mediante retorno dos produtos após o uso pelo consumidor, de forma independente do serviço público de limpeza urbana e manejo de resíduos sólidos." A lei também orienta a hierarquia de ações a serem seguidas na gestão e no gerenciamento dos resíduos sólidos. Uma das prioridades, nesse sentido, é a reciclagem - entendida como o processo de transformação de resíduos que envolve a alteração de propriedades físicas, físico-químicas ou biológicas e que dá origem a novos insumos ou novos produtos (ABRELPE, 2019).
Peixoto et al. (2019) ressalta que a lei estabelece a implantação da responsabilidade compartilhada, isto é, dividida entre os diversos participantes da cadeia de suprimentos ao longo do ciclo de vida do produto, deste a extração da matéria prima, os processos produtivos, o consumo, até o descarte final. Diante deste cenário, grandes e pequenas empresas estão preocupadas em se atualizar e acompanhar as possíveis tendências da área, agregando melhorias que podem aliar sustentabilidade ambiental e redução de custos.

Neste contexto, como foi comentado, uma das estratégias para a diminuição dos resíduos é o controle do material descartado através de sua coleta, desmonte e processamento para que retorne como suprimento ou insumo no processo industrial. Para Silva e Nascimento (2017), a coleta seletiva (CS) é uma forma de valorizar os resíduos sólidos recicláveis, uma vez que estes passam a ser selecionados na fonte geradora e não são contaminados com o restante dos resíduos sólidos urbanos domiciliares. Então, na situação pós-consumo/pós-venda, os materiais dos produtos são reinseridos no processo produtivo (quando há correto descarte, ou recolhimento por parte da indústria), possibilitando também o retorno econômico pelo reaproveitamento de material que seria descartado. Este retorno congrega os três principais pilares da sustentabilidade, porque envolve benefícios ambientais, econômicos e também sociais, na geração de renda e na seleção e encaminhamento dos resíduos.

Segundo Peixoto et al. (2019), neste cenário a logística das empresas aparece como uma ferramenta de mudança da realidade urbana. $O$ retorno do produto à cadeia de produção, após seu descarte pelo consumidor, através da CS e da LR permite o reaproveitamento da matéria prima, impactando menos o meio ambiente, gerando economia às empresas e conquistando clientes pelo apelo sustentável. Couto e Lange (2017) apontam três motivações que fundamentam a realização da LR por parte das empresas: ambiental (vantagem competitiva por meio da criação de uma imagem verde dos produtos e serviços oferecidos, utilizado como marketing), financeira (pela redução de custo com a recuperação de matéria prima, decréscimo do uso de materiais) e legal (adaptando-se à legislação vigente).

Este processo de retorno da matéria prima à cadeia de produção, base da abordagem de fluxo cíclico - a economia circular - permite o reuso, a reciclagem e o aproveitamento de partes ou componentes de um produto na fabricação de um produto novo, em múltiplos ciclos. Colaborando no sentido de eliminação de resíduos e poluição, mantendo os produtos e materiais em uso, 
baixando custos de produção e reduzindo seu impacto no ambiente. Segundo publicação de Ellen MacArthur Foundation (2017), a transição para uma economia circular requer que a indústria leve em consideração questões como a seleção de materiais, uso de componentes padronizados, projetos de produtos duráveis, design que facilite a separação dos materiais e componentes, e projetos de design que considerem possíveis aplicações de coprodutos e resíduos.

Todo este esforço em projeto de soluções a favor do fluxo cíclico e consequente promoção de vários ciclos de vida dos materiais, não é um conceito recente, a quebra de paradigma da lógica linear vem sendo comentada há décadas. $\mathrm{O}$ argumento que os produtos e seus componentes necessitam ser projetados para, ao final do ciclo de vida, terem condições de reutilização ou reciclagem, com suas propriedades não desgastadas, é defendido no âmbito acadêmico pelo menos desde a década de 1990 (AYRES e SIMONIS, 1994; VAN DER RYN e COWAN, 1996; McDONOUGH e BRAUNGART, 2002; GUIMARÃES, 2006). Período em que algumas iniciativas em coleta seletiva já haviam começado. Contudo, reconhecer que os produtos e seus componentes devem ser pensados como nutrientes tecnológicos no chamado metabolismo tecnológico, ou então voltarem à natureza como nutrientes biológicos e não como poluentes, através do metabolismo biológico como argumentam McDonough e Braugart (2002), traz a necessidade do retorno destes materiais e, portanto, exige a logística reversa.

\subsection{Panorama da Logística Reversa no Brasil}

Em 2011, quatro setores brasileiros iniciaram a implementação do processo de LR: agrotóxicos, pilhas e baterias, pneus e óleos lubrificantes (MARCHI, 2011). E, desde 2014, temos esta iniciativa também com relação às lâmpadas fluorescentes (ABRELPE, 2019).

Conforme relatório da Associação Brasileira de Empresas de Limpeza Pública e Resíduos Especiais ABRELPE (2019), o primeiro acordo setorial de LR assinado pelo Ministério do Meio Ambiente, no final de 2012, teve como parceiro o Sindicato Nacional das Empresas Distribuidoras de Combustíveis e de Lubrificantes (Sindicom). A entidade havia criado em 2005, no Rio Grande do Sul, o Instituto Jogue Limpo, que faz a logística reversa das embalagens plásticas de óleo lubrificante e de óleo lubrificante usado ou contaminado (conhecido no setor pela sigla Oluc). O programa está presente em 17 unidades da Federação, e do total, em 2018, 4.674 toneladas (98\%) tiveram destino ambientalmente adequado, das quais 4.568 foram recicladas.
Este relatório informa também que o Brasil é referência mundial na destinação adequada de embalagens de defensivos agrícolas, com um sistema de LR bem estruturado, reciclando um total de $93 \%$, e incinerando $7 \%$, sendo que tem capacidade para dar destino adequado a $100 \%$ das embalagens colocadas no mercado pela indústria (ABRELPE, 2019).

A Reciclanip é a entidade gerenciadora da LR de pneus que não podem mais ser reaproveitados (pneumáticos inservíveis) e representa os fabricantes nacionais desses produtos, atua em todo o país, impulsionada pela Resolução Conama no 416/2019, que estabeleceu a obrigatoriedade da presença de pontos de coleta nos municípios com população acima de 100 mil habitantes (ABRELPE, 2019). Em 2014, o índice de reciclagem de pneus no Brasil foi de $85 \%$, contando com cerca de 30 empresas que processam pneus no país inteiro. Em 2013 foram cadastrados 1127 pontos de coleta, sendo que destes 647 estão localizados nos municípios com população acima de cem mil habitantes. A capacidade instalada de reciclagem - em todas as unidades - hoje é de um volume superior a 460 mil toneladas por ano (CEMPRE, 2020). Do início do programa, em 1999, até o final de 2017, cerca de 4,5 milhões de toneladas de pneus inservíveis foram coletadas e corretamente destinadas, contando com 1718 postos de coleta em 2017 (ABRELPE, 2019).

Em 2014, foi assinado pela União o acordo setorial para implementar o Sistema de Logística Reversa de Lâmpadas Fluorescentes de Vapor de Sódio e Mercúrio e de Luz Mista, ficando responsável pela operacionalização do sistema a Associação Brasileira para Gestão da Logística Reversa de Produtos de lluminação (Reciclus), presente em 33 cidades de 25 estados do país. O Relatório Anual de Atividades e Resultados de 2017, informa que o sistema finalizou com 304 pontos de coleta instalados pelo Brasil e 296.3646 lâmpadas foram destinadas de forma ambientalmente correta (ABRELPE, 2019).

Outra experiência bem-sucedida é das embalagens PET (introduzidas no Brasil em 1988 e com produção crescente), em 2011, 331mil toneladas (59\%) foram recicladas (CEMPRE, 2020). Segundo Marchi (2011), o Brasil só perde em reciclagem de PET para o Japão (que reciclou 77,9\% no mesmo período). Porém apesar destes números, 45,2\% das PET seguiram para aterro, representando ainda uma quantidade nociva à natureza. Em 2010, a Coca-Cola lançou no Brasil a PET feita com etanol da cana de açúcar, substituindo parte do petróleo utilizado como insumo (podendo diminuir em 25\% as emissões de CO2) e, lançou também, a PET retornável utilizando como atrativo o preço (MARCHI, 2011). 
Ao contrário das garrafas plásticas, o alumínio utilizado em latas de bebidas, não se degrada durante o processo de reciclagem, e pode ser utilizado para o mesmo fim com $100 \%$ de aproveitamento, possuindo um preço mais atrativo. Em 2015, 97,9\% do total das latas de alumínio disponibilizadas no mercado brasileiro foram recicladas. Além de reduzir os resíduos sólidos que vão para aterros, sua reciclagem proporciona um significativo ganho energético, visto que para reciclar 1 tonelada de latas se gasta $5 \%$ da energia necessária para produzir a mesma quantidade de alumínio pelo processo primário (CEMPRE, 2020). Assim, entendemos que, apesar destes materiais apresentarem pontos negativos em relação às questões ambientais na sua extração e manufatura, por outro lado, possuem propriedades adequadas aos fins que se destinam nos produtos e apresentam soluções de reciclagem viáveis que já estão implantadas no país.

\subsection{Coleta Seletiva no Brasil}

O documento do Instituto Brasileiro de Geografia e Estatística que apresenta os Indicadores de desenvolvimento sustentável, com dados do período de 2000 a 2008 , revela que $19,5 \%$ dos municípios brasileiros possuem CS (IBGE, 2012). Conforme IBGE (2015), este indicador sobre CS de lixo, apresentado na edição de 2012, "foi retirado devido à impossibilidade de atualização". As regiões Sul e Sudeste apresentaram, em 2008, os maiores percentuais de municípios com CS $(41,3 \%$ e $25,9 \%$ do total, respectivamente), superiores ao índice nacional, com destaque para o Estado do Paraná (52,1\%). Por outro lado, nas demais regiões, menos de $8 \%$ dos municípios realizavam CS (IBGE, 2012).

Este documento apresenta também um gráfico com a proporção do lixo coletado com destinação final adequada (disposição do lixo em aterros sanitários, seu envio a estações de triagem, reciclagem e compostagem, e sua incineração em equipamentos, segundo procedimentos próprios), onde as regiões Sudeste e Sul do país apresentam os maiores índices de, respectivamente, $81,8 \%$ e $82,9 \%$, e os menores índices estão nas regiões Norte $(36,1 \%)$, Nordeste $(44,3 \%)$ e Centro-Oeste (29,5\%). O RS em especial tem índice acima de $95 \%$. A CS de lixo e a reciclagem estão associadas e contribuem para o aumento da fração do lixo coletado que é adequadamente disposto (IBGE, 2012).

O último Panorama dos Resíduos Sólidos no Brasil, divulgado pela ABRELPE (2019), 73,1\% dos municípios brasileiros tem iniciativas de CS, e destacam-se os municípios das regiões sul e sudeste com $90,9 \%$ e $89,7 \%$ respectivamente (Figura 2).
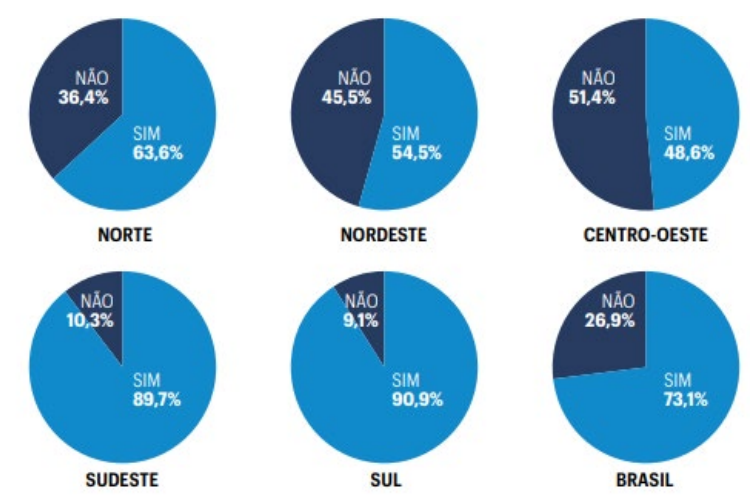

Figura 2: Distribuição dos municípios com iniciativa de coleta seletiva. Fonte: ABRELPE (2019)

A região sudeste é onde se gera maior quantidade de resíduos per capita no país, e a região sul é a que menos gera resíduos per capita, como pode-se verificar nos dados divulgados no documento da ABRELPE (2019), apresentados na Figura 3.

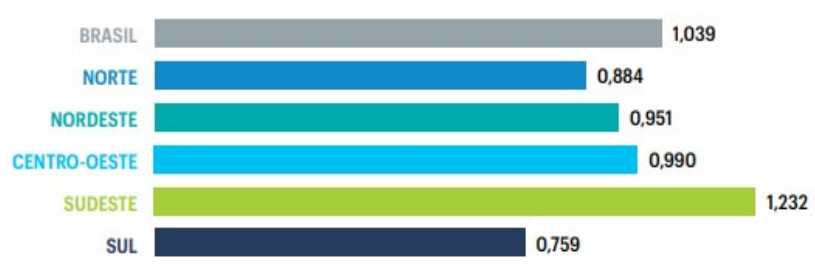

Figura 3: Geração de resíduos sólidos urbanos per capita nas regiões (kg/habitante/dia). Fonte: ABRELPE (2019)

Mesmo depois de dez anos de sua criação, a aplicação da Lei 12.305 ainda é uma realidade distante na grande maioria das cidades, conforme reportagem no Jornal do Comércio (LESINA, 2018), ainda existem 1600 lixões ativos no Brasil - dados de 2017. Segundo dados da ABRELPE (2019), 42 municípios da região sul ainda utilizam o lixão como disposição final para os resíduos sólidos urbanos.

Somado às questões de infraestrutura estão as definições conceituais. As definições de rejeito, lixo e resíduo, são diferentes, segundo Calderoni (2003): resíduo é o material que sobra de um processo produtivo; rejeito é o material que, após um processo de seleção, não é aproveitado; e lixo é o material sólido que não passa por nenhuma seleção e é descartado pelo proprietário. Este entendimento é importante para ações de coleta seletiva e reaproveitamento, afinal as pessoas precisam entender o caminho dos resíduos para colaborarem materializarem as ações da administração municipal.

O Departamento Municipal de Limpeza Urbana de Porto Alegre (PMPA - DMLU, 2020) os categoriza em quatro grupos: (i) os resíduos orgânicos domiciliares (resíduos de origem 
animal ou vegetal) e rejeitos (materiais que não podem ser reaproveitados, como papel higiênico, fraldas, cigarro, dentre outros); (ii) os recicláveis (plástico, vidro, papel seco e metal); (iii) os resíduos especiais (poda de arvore, caliça, entulho); e (iv) os resíduos perigosos (lâmpadas fluorescentes, pilhas e baterias, medicamentos, cartuchos e toners, óleos).

Conforme estimativas realizadas com base na série histórica, o Brasil alcançará uma geração anual de 100 miIhões de toneladas por volta de 2030. A melhora quantitativa e qualitativa na cobertura de coleta também é uma tendência consolidada em todas as regiões, mas há um contingente considerável de pessoas que ainda não são alcançadas por serviços regulares de coleta porta a porta. Enquanto o mundo avança em direção a um modelo mais moderno e sustentável de gestão de resíduos, o Brasil continua apresentando as deficiências verificadas há vários anos, ficando abaixo dos indicadores médios de nações da mesma faixa de renda e desenvolvimento (ABRELPE, 2019).

\subsection{Coleta Seletiva em Porto Alegre}

Com relação à limpeza urbana e à gestão dos resíduos sólidos, Porto Alegre passou por todas as etapas comuns à maioria dos municípios brasileiros. Houve cenários históricos de intensa degradação ambiental e humana decorrente das relações indivíduos/resíduos/ ambiente, convergindo, há cerca de duas décadas, a uma qualificação técnico-gerencial que elevou o Município ao patamar de modelo latino-americano em gestão de resíduos sólidos (PMPA - DMLU, 2013).

A Capital do Rio Grande do Sul, conta com o DMLU (Departamento Municipal de Limpeza Urbana) responsável pela coleta regular domiciliar (de orgânicos e rejeitos), realizadas em $100 \%$ das ruas da cidade, através de caminhões compactadores ou através de coleta mecanizada, nos 19 bairros onde estão distribuídos os 2400 unidades de contêineres (para o descarte de resíduos orgânicos), este material é levado para unidades de transbordo para seguir em caminhões de maior capacidade para o aterro sanitário em Minas do Leão (distante aproximadamente $80 \mathrm{~km}$ de Porto Alegre), segundo dados do site da Prefeitura, são levados em média 43000 toneladas/mês (PMPA - DMLU, 2020).

O DMLU é responsável também pela coleta seletiva (recicláveis), realizada em $100 \%$ das ruas onde comporta a entrada de caminhões, de duas a três vezes por semana, dependendo do bairro (Figura 4 (a)). Este material coletado é enviado para as Unidades de Triagem, onde o resultado da comercialização dos resíduos selecionados é dividido entre os integrantes das associações e cooperativas que fazem a gestão de cada unidade (Figura 4 (b)). A cidade conta com 16 Unidades de Triagem cadastradas.

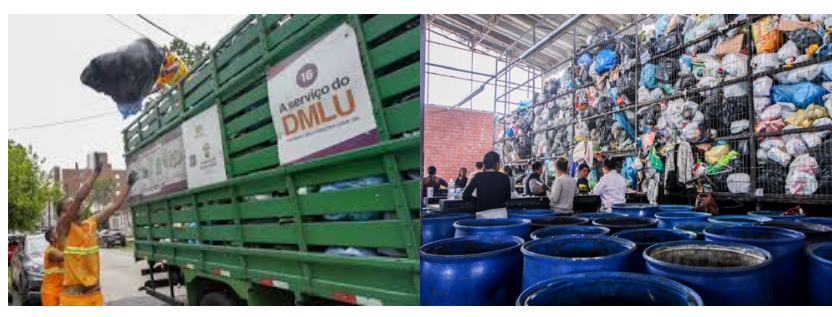

(a)

(b)

Figura 4: (a) CS com caminhões do DMLU e (b) Unidade de Triagem Fonte: site Prefeitura de Porto Alegre (http://www.portoalegre.rs.gov.br)

Em uma estimativa feita pelo DMLU em 2015, pesando o total de material que chega nas estações de triagem e o material total vendido pelas cooperativas, concluiu que de $25 \%$ a $30 \%$ do material total coletado era rejeitado e acabava sendo direcionado para o aterro sanitário. Silva e Nascimento (2017) citam um estudo, ainda não publicado pelo DMLU, onde existem dados que nos últimos anos, em média 30\% do material depositado em aterro sanitário era de resíduos potencialmente recicláveis que acabam não aproveitados, devido à separação incorreta, ou por serem materiais de baixíssimo custo, portanto não apresentam retorno financeiro para as cooperativas e são descartados.

A cidade conta também com 8 ECOPONTOS, que são Unidades de Destino Certo gerenciados pelo DMLU, onde a população pode levar resíduos de construção civil, de podas, móveis, pneus, eletrodomésticos, sucata, etc. Porto Alegre conta também com a Unidade de Compostagem (onde é realizado o reaproveitamento de resíduos orgânicos), além de serviços de limpeza urbana como varrição manual e mecanizada, capina, limpeza de viadutos, etc (PMPA - DMLU, 2013).

Para dar destino aos resíduos perigosos (que são de responsabilidade do gerador), existem também pontos de entrega voluntária de óleos de fritura exauridos (PEOF's). Estes resíduos são reciclados, através convênio firmado entre o DMLU e estabelecimentos industriais licenciados, tendo fins diversos, como aproveitamento energético, fabricação de rações e fabricação de biodiesel (PMPA - DMLU, 2020).

A partir de um convênio firmado com a empresa Trade Recicle, a Prefeitura constituiu pontos para entrega voluntária de resíduos eletrônicos de geradores pessoas físicas, que serão reciclados pela conveniada. Existe também um projeto de entrega voluntária de pilhas e baterias (Projeto Papa-pilhas do Banco Santander), onde o material arrecadado segue para uma empresa localizada no estado de São Paulo especializada no tratamento de tais resíduos. Assim como pontos de entrega voluntária de fármacos com prazo de validade vencido, pelos geradores pessoas físicas. 
Implantado pela Rede Panvel de Farmácias, nesta iniciativa os medicamentos arrecadados seguem para um aterro licenciado para resíduos industriais perigosos, sob custeio da própria de rede de farmácias (PMPA - DMLU, 2013).

\section{CONTRIBUIÇÕES PARA O PROJETO QUE INCENTIVE A LOGÍSTICA REVERSA}

Este trabalho apresenta um estudo exploratório, que teve como finalidade buscar informações sobre os atuais serviços de coleta de resíduos sólidos urbanos no Brasil, da atual situação de aplicação da Lei Federal 12.305 e o que está sendo feito em logística reversa no Brasil e na cidade de Porto Alegre.

O estudo foi realizado por meio de pesquisa bibliográfica, buscando relatórios e panoramas publicados por órgãos do governo e associações representantes de entidades relacionadas ao tema, assim como artigos de periódicos, matérias de revistas e jornais, e sites corporativos.

Esta compilação de informações serve para a reflexão sobre os desafios da implantação da CL e da LR no país, já que estas são as bases para um projeto sistêmico de economia circular. Revisando estas iniciativas que vêm sendo implementadas por décadas é possível vislumbrar possibilidades de melhorias e mesmo de implementação rápida em cidades onde estas iniciativas ainda não existam.

\subsection{Desafios para a implementação de sistemas de Logística Reversa no país}

O trabalho publicado por Couto e Lange (2017), que apresenta uma análise dos sistemas de LR no Brasil, mostra que sua implementação ainda enfrenta desafios, em relação aos aspectos: (i) políticos e legais; (ii) operacionais; e (iii) sociais relacionados à mão de obra e à participação da população.

Os autores destacam alguns pontos críticos para que os acordos setoriais firmados entre o Governo Federal e os setores produtivos sejam factíveis de serem cumpridos. Dentre os aspectos políticos e legais, os autores citam: revisão da legislação em relação ao gerenciamento de resíduos perigosos, estabelecimento de metas para a utilização de matéria prima secundária, promoção do mercado de recicláveis por meio de incentivos fiscais ao uso de material reciclado, linhas de crédito para recicladoras, dentre outros. E ressaltam que questões sobre adequação de legislação e normalização, licenciamento ambiental, entre outros, exigem atuação direta do Governo Federal, tanto como elemento articulador entre os elos da cadeia produtiva, quanto como regulamentador e fiscalizador do cumprimento dos acordos (COUTO e LANGE, 2017).
Dentre os aspectos operacionais, os autores citam: fomentar a pesquisa para o desenvolvimento de novas técnicas de reciclagem, estabelecimento de taxas de reciclabilidade para embalagens, estabelecimento de critérios de qualidade para produtos elaborados com matéria prima secundária, necessidade de conhecimento do parque reciclador nacional, dentre outras. Dentre os aspectos sociais, destacam: capacitação da mão de obra e das organizações de catadores, criação de amplo programa de educação ambiental e conscientização da população, promoção da mudança de cultura do consumidor e do comerciante quanto à devolução dos resíduos (COUTO e LANGE, 2017).

Outras questões que envolvem legislação e especificamente os Acordos Setoriais são comentados por Guarnieri et. al. (2020), os autores argumentam que Lei Federal 12.305 traz a ideia de economia circular, apesar de não trazer explicitamente o conceito, devido ao fato de o conceito ter sido cunhado posteriormente. Um dos instrumentos para colocar em prática esta legislação são os Acordos Setoriais, que objetivam implementar a LG. Estes acordos são contratos entre autoridades governamentais, fabricantes, importadores, distribuidores e comerciantes que devem compartilhar responsabilidade sobre o ciclo de vida dos produtos (GUARNIERI et. al., 2020). Os acordos em si representam um desafio, que relacionam e representam as pressões entre os agentes públicos, os interesses dos produtores e da sociedade.

\subsection{Problemas enfrentados no processo de co- leta seletiva}

No Brasil, os altos níveis de reciclagem nem sempre estão associados à educação e à conscientização ambiental. Muitas vezes o alto valor das matérias-primas e a presença de uma massa de trabalhadores sem qualificação e poucas opções de emprego são fatores que explicam o grande número de pessoas envolvidas na atividade. A maior parte da coleta é feita por catadores, autônomos ou associados em cooperativas, que retiram do lixo os materiais de mais alto valor em condições de trabalho precárias e com baixa remuneração. Por isso, materiais como papel, vidro, embalagens PET, latas de aço e embalagens longa vida, de mais baixo valor de mercado, apresentam índices de reciclagem bem menores que as latas de alumínio. Neste cenário, a coleta seletiva e a conscientização da população para separar os resíduos antes de descartá-los pode aumentar não apenas a eficiência da reciclagem como também trazer melhorias na qualidade de vida de catadores e de outros trabalhadores que lidam com resíduos (IBGE, 2012). 
O artigo de Silva e Nascimento (2017), conta a história da coleta seletiva na cidade de Porto Alegre, baseado também em entrevistas com antigos gestores da cidade. Os autores destacam alguns problemas ainda existentes apontados pelos entrevistados: que "...a gestão integrada de resíduos deveria voltar-se para a diminuição da produção de resíduos e caberia às empresas assumirem maior responsabilidade com a logística reversa dos produtos que comercializam..." e que "...o sistema de coleta seletiva poderia estar mais desenvolvido e atribuem a culpa à falta de investimentos em divulgação e conscientização da população. Outros defendem mudanças no modelo de coleta e maior investimento na mecanização do processo de separação dos resíduos...".

Natusch (2017) aponta os gargalos para que a cidade aproveite melhor seus resíduos. Segundo o autor, Porto Alegre faz a triagem de 100 toneladas de lixo reciclável por dia, mas "para que o sistema seja mais efetivo, e para gastar menos dinheiro com materiais sem chance de aproveitamento, é preciso melhorar a qualidade do resíduo reciclável recolhido - menos de $5 \%$ é efetivamente aproveitado." Este trecho aponta que falta mais consciência por parte da população na separação de seus resíduos. A matéria aborda também as questões dos atravessadores, pessoas que compram o material dos carrinheiros e catadores individuais, interceptando o material reciclável mais valioso na fonte, não deixando que chegue às unidades de triagem, cooperativas credenciadas junto à prefeitura. Este processo acaba por prejudicar a renda dos cooperados, fazendo com que as cooperativas reduzam o número de trabalhadores, causando uma tendência de "exclusão social profunda".

Goldenberg (2018) relata que a quantidade de trabalhadores nos galpões conveniados com a Prefeitura de Porto Alegre, que separam os resíduos recolhidos na coleta seletiva do DMLU, vem caindo por dois motivos: a falta de pagamentos da prefeitura para a manutenção dos locais, e a baixa quantidade de material recebido devido à "coleta seletiva clandestina" O autor apresenta os quantitativos desta queda segundo dados do DMLU: em 2015 o total de material recebido em todas as Unidades de Triagem era de 27 mil toneladas em 2014, 28 mil toneladas; em 2017 foram 21 mil toneladas em 2016 e 20 mil toneladas. Houve uma redução de $30 \%$ do material e o número de catadores foi reduzido à metade.

Castro (2020) relata que a população de Porto Alegre produz, em média, quase duas mil toneladas de resíduos diariamente. Deste total, mais de mil toneladas correspondem a lixos orgânicos e rejeitos. Dos resíduos recicláveis a cidade só recicla cerca de $6 \%$, de acordo com dados do DMLU. Isto ocorre devido à mistura de resíduos orgânicos no material que poderia ser reciclado e acaba por ser descartado para o aterro sanitário. $\mathrm{O}$ autor aborda também a questão dos materiais, consumidos em grande quantidade pela população e que, na teoria, são recicláveis, mas não possuem valor de venda ou compradores no Rio Grande do Sul e também acabam virando rejeito, como é o caso do isopor, pets coloridos, alguns copos descartáveis e embalagens de salgadinhos ou biscoitos. O isopor, por exemplo, só é reciclado em uma empresa no Espírito Santo, inviabilizando economicamente o transporte de cargas deste material, que custa muito pouco. Portanto, muitos materiais que são recicláveis, mas não têm "valor de reciclagem" vão para o aterro.

Atualmente, os materiais com maior valor comercial para venda em Porto Alegre são garrafas pet brancas ou verdes, latinhas, bombonas de clorofila e embalagens de xampu (CASTRO, 2020). Como já constatado por Goldenberg (2018), Castro (2020) também fala da existência da coleta irregular organizada, chamada de "coleta clandestina", que atua arrecadando os resíduos recicláveis de maior valor comercial antes que a Coleta Seletiva oficial da Prefeitura passe nas vias públicas para recolher os resíduos descartados pela população, muitas vezes vendidos por alguns condomínios ou grandes geradores, como empresas privadas, diretamente a estes clandestinos.

Outra questão apontada pelo DMLU é a o aparecimento de novos materiais de embalagens, pois não há tecnologia ou viabilidade econômica para reciclá-los. Isto concerne especialmente aos designers. Silva e Nascimento (2017) apontam que, diante desta situação, as empresas deveriam assumir a obrigação do descarte correto de seus produtos, o que faria que planejassem todo o ciclo de vida dos produtos e embalagens, não repassando o problema da destinação final para o poder público.

Segundo o relatório do BNDES (2010), o município de Porto Alegre, que a mais de 30 anos planejou e implantou o sistema de CS e as unidades de triagem com o objetivo da inclusão social dos catadores, apresenta um sistema que necessita melhorias e novas tecnologias que integrem o sistema de gestão. Depois de uma década deste diagnóstico atualmente a necessidade de informar a população chama atenção. No site da prefeitura de Porto Alegre (em notícia postada em 23/05/2019) sobre os avanços da LR em descarte de produtos, a diretora do DMLU Mariza Reis, destacou que "Há muita divulgação para o consumo, mas nada de divulgação para a LR. Falta investir mais em educação e esclarecer a população sobre os impactos do descarte incorreto" (PMPA - DMLU, 2020). 
Estudos internacionais mostram que a coleta seletiva é incentivada pela informação acerca do valor agregado dos resíduos, por penalidades que tenham meta de promover a separação adequada e pela motivação pessoal (ZHENG et. al., 2020). Segundo os autores, a questão da motivação aumenta ou pelo menos o comportamento a favor da coleta seletiva é reforçado quando a comunidade compartilha opiniões e percepções positivas sobre o tema, inclusive pelas redes sociais. Assim, iniciativas que aproximem vizinhos e ressaltem a importância do encaminhamento às unidades de triagem podem gerar resultados no sentido de assegurar que o fluxo cíclico realmente aconteça.

\section{CONSIDERAÇÕES FINAIS}

Dentre as principais vantagens da reciclagem, destaca-se o aumento da vida útil dos aterros sanitários, a redução do consumo de energia e recursos naturais, graças ao aproveitamento dos resíduos pela indústria de transformação, o que também leva à diminuição dos custos de produção. Além disso, o consumidor vem exigindo uma postura mais ética e responsável por parte das empresas com relação às questões ambientais. Desta forma, a aplicação da LR tende a trazer benefícios proporcionando redução de custos com matéria-prima e suprimentos e promovendo a responsabilidade socioambiental. Promovendo a responsabilidade socioambiental.

Em Porto Alegre desde 1989, tem-se a preocupação em extinguir os lixões, visto que não era mais uma alternativa viável para a cidade, neste meio tempo tornou-se referência no gerenciamento de resíduos, mesmo com todos os problemas ainda existentes. Porém, após mais de 30 anos de Coleta Seletiva na cidade esperava-se que a cultura de separação estivesse introjetada na consciência da população portoalegrense, porém, não é o que acontece. Isto demonstra a necessidade de contínuo trabalho através de campanhas intensas e frequentes de conscientização em gerar menos resíduo e como descartá-lo, que pode ser fortalecido no projeto de produtos.

Outra questão é a necessidade de fiscalização forte para inibir a prática das coletas clandestinas, o que prejudica o trabalho e sustento das cooperativas e colabora com as questões sociais. O futuro da CS parece estar associado à implementação das leis já aprovadas, que responsabilizam cada elo da cadeia da LR, onde a responsabilidade do resíduo, é de quem inicia o processo produtivo. $\mathrm{O}$ consumidor tem a responsabilidade de fazer a separação, e quem produz e comercializa deve implantar a LR. Assim, quem gerencia o resíduo é a iniciativa privada e o governo tem o dever de fiscalizar.
A gestão de resíduos de forma moderna e avançada passa também pela aplicação de estratégias bem-sucedidas em outros países. Por exemplo, a implementação de um sistema de remuneração direta pelos usuários, que garante a sustentabilidade econômica e propicia maior justiça social (pois é baseada no pagamento conforme a geração e utilização dos serviços).

Frente às demandas impostas pela PNRS no Brasil, é necessário investimentos permanentes, em tecnologia, educação e em gestão, e estas ações derivam de pesquisa e desenvolvimento de novas máquinas para a produção, considerando o conceito de ecodesign, que busca a redução da geração de resíduos e consumo de energia e água, em todo o processo para que a economia circular possa ser uma realidade.

\section{REFERÊNCIAS}

ABRELPE - Associação Brasileira de Empresas de Limpeza Pública e Resíduos Especiais. Panorama dos resíduos Sólidos no Brasil 2018-2019. (2019) Disponível em: https://abrelpe.org.br/panorama/ . Acesso em: 20 out.2020.

AYRES R. U.; SIMONIS. U. E. Industrial metabolism: restructuring for sustainable development. Tokyo; New York: United Nations University Press. 1994. XIV, $376 \mathrm{p}$.

BNDES - Banco Nacional de Desenvolvimento. Produto 4: relatório final do perfil institucional, quadro legal e políticas públicas relacionados a resíduos sólidos urbanos no Brasil e no exterior. Pesquisa Científica BNDES FEP No02/2010 (2010). Disponível em: https://web.bndes.gov.br/bib/jspui/ handle/1408/13076 Acesso em: 27 out. 2020.

BRASIL Lei Federal n 12.305, de 2010. Institui a Política Nacional de Resíduos Sólidos. Disponível em: http:// www.planalto.gov.br/ccivil_03/_ato2007-2010/2010/ lei/l12305.htm. Acesso em: 20 jun. 2020.

CALDERONI, S. Os bilhões perdidos no Lixo. 4 ed. São Paulo: Editora Humanitas. 2003.

CASTRO, A. Com separação incorreta, baixo preço de venda e 'coleta clandestina', Porto Alegre só recicla $6 \%$ do lixo. Jornal Sul21, publicada em 7/02/2020. Disponível em https: <//www.sul21.com.br/ caminhos-do-lixo/2020/

1/com-separação-incorreta-baixo-preco-de-venda-e-coleta-clandestina-porto-alegre-so-recicla-6-do-lixo/> Acesso em: 15 ago. 2020.

CEMPRE - COMPROMISSO EMPRESARIAL PARA A RECICLAGEM. (2020) Artigos e Publicações: Fichas 
técnicas. Disponível em: <http://cempre.org.br/artigo-publicacao/ficha-tecnica> Acesso em: 25 out. 2020. COUTO, M. C. L.; LANGE, L. C. Análise dos sistemas de logística reversa no Brasil. Engenharia Sanitária e Ambiental. vol.22 no.5 Rio de Janeiro Sept. / Oct. 2017. Disponível em: https://doi.org/10.1590/S141341522017149403. Acesso em: 22 out. 2020.

ELLEN MACARTHUR FOUNDATION Economia circu-

lar. 2017. Disponível em: https://www.ellenmacarthurfoundation.org/pt/economia-circular/conceito Acesso em: 07 jan. 2021.

GOLDENBERG, F. O lixo não chega: renda de recicladores cai pela metade nos últimos meses em porto alegre. Jornal Zero Hora, publicada em 29/05/2018. Disponível em: https://medium.com/felipegoldenb. Acesso em: 15 ago. 2020.

GUARNIERI, P. Logística Reversa: em busca do equilíbrio econômico e ambiental. Recife: Ed.Clube de Autores, 2013. $307 \mathrm{p}$.

GUARNIERI, P.; STREIT- CERQUEIRA, J.A.; BATISTA, L.C. Reverse logistics and the sectoral agreement of packaging industry in Braziltowards a transition to circular economy. In: Resources, Conservation \& Recycling 153, 2020.

Monográfica Ergonomia).Porto Alegre: FEEng/UFRGS, v.2. 2006.

IBGE - Instituto Brasileiro de Geografia e Estatística (2012) Indicadores de Desenvolvimento Sustentável, 2012. Disponível em: https://biblioteca.ibge.gov.br/visualizacao/ livros/liv59908.pdf Acesso em: 24/10/2020 IBGE - Instituto Brasileiro de Geografia e Estatística (2015) Indicadores de Desenvolvimento Sustentável, 2015. Disponível em: https://biblioteca.ibge.gov.br/visualizacao/livros/liv94254.pdf Acesso em: 24/10/2020 LESINA, E. Logística Reversa: A saída é pelo caminho inverso. Jornal do Comércio, publicada em 26/11/2018. Disponível em: https://www.jornaldocomercio.com/ _conteudo/cadernos/impresas_e_negocios/2018/11/ 657441-a-saida-e-pelo-caminho-inverso.html Acesso em: 20 jun. 2020.

McDONOUGH, W.; BRAUNGART, M. Cradle to cradle: remaking the way we make things. New York: North Point Press. 2002. 193 p.

MARCHI, C. M. D. F. Cenário mundial dos resíduos sólidos e o comportamento corporativo brasileiro frente à logística reversa. Perspectivas em Gestão \& Conhecimento, João Pessoa, v. 1, n. 2, p. 118 - 135, jul/ dez. 2011. Disponível em: https://dialnet.unirioja.es/

servlet/articulo?codigo $=4262882$ Acesso em: 20 jun 2020.

NATUSCH, I. Porto Alegre está longe da eficiência em reciclagem. Jornal do Comércio, publicado em 22/08/2017. Disponível em: https://www.jornaldocomercio.com/_conteudo/2017/08/geral/580827-porto-alegre-esta-longe-da-eficiencia-em-reciclagem.html Acesso em: 15 ago. 2020.

PEIXOTO, B. L. C.; SOUZA, I. G. S.; FERREIRA, K. N. S.; FARIAS, N. M. O.; DANTAS, N. V.; CARVALHO, R. S. S. A logística reversa no Brasil: responsabilidade ambiental e a perspectiva econômica. XI SIMPROD - Simpósio de Engenharia de Produção de Sergipe, novembro, 2019. Anais. P. 164 a 177. Disponível em: https://ri.ufs. br/bitstream/riufs/12570/2/ LogisticaReversaBrasil.pdf Acesso em: 20 jun. 2020.

PREFEITURA DE PORTO ALEGRE - DMLU. Plano Municipal de Gestão Integrada de resíduos Sólidos. Volume 1 - Diagnóstico e Prognóstico. Porto Alegre, 2013. Disponível em: http://lproweb.procempa.com.br/pmpa/prefpoa/dmlu/usu_doc/pmgirs _porto_alegre_volume_1.pdf Acesso em 20 set. 2020. PREFEITURA DE PORTO ALEGRE - DMLU. Site Departamento Municipal de Limpeza Urbana, 2020. Disponível em: http://www2.portoalegre.rs.gov.br/ dmlu/ Acesso em: 20 jun. 2020.

SILVA, C. S.; NASCIMENTO, L. F. M. 25 Anos da Coleta Seletiva de Porto Alegre: História e Perspectivas. Revista Gestão e Desenvolvimento - FEEVALE, V. 14 no. 2, Novo Hamburgo, dezembro, 2017. Disponível em: https://periodicos.feevale.br/seer/index.php/ revistagestaoedesenvolvimento/article/view/1135. Acesso em: 20 jun. 2020.

SOUZA, M. T. S.; DE PAULA, M. B.; SOUZA-PINTO, H. O papel das cooperativas de reciclagem nos canais reversos pós-consumo. Revista de Administração de Empresas, vol 52, no. 2, São Paulo, 2012. Disponível em: https://doi.org/10.1590/S0034-75902012000200010 Acesso em: 20 jun. 2020.

VAN DER RYN, S.; COWAN, S. Ecological design. Washington, D.C.: Island Press. 1996. XV, 201 p. p. ZHENG, J.; MA, G.; WEI, J.; WEI, W.; HE, Y.; JIAO, Y.; HAN, $X$. Evolutionary process of household waste separation behavior based on social networks. In: Resources, Conservation and Recycling, vol. 161, oct.2020. 


\section{AUTORES}

ORCID: 0000-0003-3334-8217

ANELISE TODESCHINI HOFFMANN, MsC. | Universidade Federal do Rio Grande do Sul | Doutoranda no Programa de Pós Graduação em Design | Porto Alegre, RS - Brasil | Correspondência para: Rua Bernardo Pires 475/ 301, Bairro Santana, Porto Alegre - RS, 90620-010 | e-mail: anelise.hoffmann@ufrgs.br

ORCID: 0000-0003-2109-0677

JOCELISE JACQUES DE JACQUES, Dra. | Universidade Federal do Rio Grande do Sul | Docente do Programa de Pós Graduação em Design | Porto Alegre, RS - Brasil | Correspondência para: Av. Nilo Peçanha, 550/1501, Bairro Petrópolis, Porto Alegre -RS, 90470-000 | e-mail: jocelise.jacques@ufrgs.br

\section{COMO CITAR ESTE ARTIGO}

HOFFMANN, Anelise Todeschini; JACQUES, Jocelise Jacques de. Iniciativas De Coleta Seletiva E Logística Reversa Em Porto Alegre Como Base Para Economia Circular. MIX Sustentável, [S.I.], v. 7, n. 4, p. 19-30, set. 2021. ISSN 24473073. Disponível em:<http://www. nexos.ufsc.br/index.php/mixsustentavel $>$. Acesso em: dia mês. ano. doi:https://doi.org/10.29183/2447-3073. MIX2021.v7.n4.19-30. 
